\title{
KEY SUCCESS FACTORS FOR STATISTICAL LITERACY POSTER COMPETITIONS
}

\author{
STEVE MACFEELY \\ UN Conference on Trade and Development and University College Cork \\ steve.macfeely@unctad.org \\ PEDRO CAMPOS \\ University of Porto and Statistics Portugal \\ pedro.campus@ine.pt \\ REIJA HELENIUS \\ Statistics Finland \\ reija.helenius@stat.fi
}

\begin{abstract}
Statistical literacy is complex and multifaceted. In every country, education and numeracy are a function of a multitude of factors including culture, history, and societal norms. Nevertheless, since the launch of the International Statistical Poster Competition (ISLP) in 1994, a number of patterns have emerged to suggest there are some common or universal success factors in running statistical literacy competitions involving schools, universities, statistical offices, and many other institutions. This paper outlines some of those factors, such as institutional cooperation, celebrating participation and success, improvement of statistical literacy in the local schools, support for teachers, the involvement of national statistics institutes, and use of technology. These factors have been identified from our own experience running the competition and from articles submitted to the ISLP newsletters. Statistical literacy is a complex phenomenon, and so this is neither an exhaustive list of key factors nor a formula for success, but rather an overview of recurring themes across countries participating in the competition around the world.
\end{abstract}

Keywords: Improving statistical literacy; Key success factors; Poster competitions; International Statistical Literacy Project

\section{INTRODUCTION}

"Statistics and general numeracy are increasingly becoming a necessary competency in modern life and the lingua franca of day-to-day transactions. Hence, improving statistical literacy is essential if future economies are to function efficiently and if citizens are to actively participate in and contribute to society." (MacFeely, 2016, 799).

Statistics involves tools and ideas that students can use in order to react intelligently to quantitative information in the world around them (Garfield, Ben-Zvi, Chance, Medina, Roseth, \& Zieffler, 2008; Ben-Zvi \& Garfield, 2004). The ability to collect, organise, describe, display, and interpret data, as well as to make decisions and predictions on the basis of that information, is a skill that is ever more important in a data-driven society increasingly reliant on technology and communication (Walsh Jr.,

Statistics Education Research Journal, 16(1), 202-216, http://iase-web.org/Publications.php? $p=$ SERJ

(C) International Association for Statistical Education (IASE/ISI), May, 2017 
2011). Data can be used to create an engaging, informative, and compelling story (Nussbaumer Knaflic, 2015). Data visualisations are increasingly important as now major data providers are offering powerful visualisations in the hope of making their data more accessible. For instance, international organisations such as the OECD (Organisation for Economic Cooperation and Development) have made data accessible via Gapminder and eXplorer in order to make important political or global targets such as the United Nations (UN) Millennium Development Goals more accessible through interactive dashboards, to encourage public engagement (Ridgway \& Smith, 2013). The UN Conference on Trade and Development (2016) has also published the first statistical report on the Sustainable Development Goals (SDG) - this online report has used a variety of motion charts, interactive maps and infographics to visualise and explain the baseline 2016 situation for a selection of SDG targets. A group of experts has prepared a guide on how to make data meaningful (see UN Economic Commission for Europe, 2012).

Storytelling with data improves visual and statistical literacy. The International Statistical Literacy Project (ISLP) is intended to contribute to the promotion of statistical literacy across the world; among children, adolescents and adults from all walks of life. To this end, the ISLP supports, creates and participates in statistical literacy and promotion activities; it is operated under the aegis of the International Association for Statistical Education (IASE), the education branch of the International Statistical Institute (ISI). Today, it has coordinators in 90 countries located on every continent. The ISLP combines several projects under one roof, each of them focused on a different aspect of statistical literacy.

The projects are coordinated by expert volunteers (known as country coordinators) who highlight news, compile resources, and initiate activities dedicated to improving statistical literacy in their country or region. The best-known project is probably the Poster Competition (ISLP, n.d.), which invites school students from around the world to design a statistical poster, illustrating their ability to use, analyse, interpret, and communicate findings. Designing a poster that clearly communicates a message, using appropriate data visualisation, is the ultimate goal of the ISLP poster competition. Posters should illustrate the correct usage of data, including analysis, interpretation and communication of statistics or statistical information. This competition is intended to introduce young people to the joys of investigation and research.

This paper outlines some key success factors in running a statistical literacy competition, such as: institutional cooperation; celebrating participation and success; the importance of national competitions; support for teachers; the involvement of national statistics institutes (NSIs); the supporting role of academia; and use of technology. These factors have been identified from our long-term experience running the competition and from articles submitted to the ISLP newsletters (see ISLP, n.d.). As noted above, education and statistical literacy are complex phenomena, and so this is not an exhaustive list of success factors or a formula for success, but rather an overview of some recurring themes across many countries participating in the ISLP competition.

\section{THE ISLP NEWSLETTER}

The key success factors presented in this paper were identified from articles in the ISLP newsletter. The newsletter was launched in 2008. That year, four volumes followed. Since then the publication schedule has settled down with typically one or two volumes published per year. Newsletters include articles in a variety of languages, although most of them are in English. Recent years have witnessed a considerable growth in the number of articles submitted for publication, and a widening geographic coverage, including 
developing countries. For example, the December 2016 issue comprises 43 articles from around the world, including 27 from developing countries, of which 12 were from Africa.

Despite the growing diversity with respect to the origin of the articles, the winners of the global ISLP poster competition have always come from developed countries: Canada, Finland, South Korea, Finland again, Australia, and Ireland won the competitions in the two age groups held in 2011, 2013 and 2015. The success of developed countries both in regard to the competition and in the development of national infrastructure geared towards improved statistical literacy is reflected in the presentation of the success factors that follows. Although it should be noted that some developing countries have enjoyed podium success with the ISLP - notably Malawi and Lesotho in 2008/09. It is hoped that other countries with less experience in this field can take some inspiration from these experiences.

Success factors have been identified from a literature review of the ISLP newsletters from 2014 and 2015. There are two reasons for limiting the review to these editions: Firstly, in recent years the newsletter has enjoyed a significant broadening of global coverage and now provides more inclusive reportage; and secondly, while in earlier editions articles tended to provide updates on events, in the most recent years articles have become more reflective.

\section{STATISTICAL LITERACY COMPETITIONS}

While mathematics has a long tradition of competitions, there was no comparable custom in statistics with the notable exception of Japan, where the National Statistics Graph Competition has been running since 1953. The International Mathematical Olympiad, first held in Romania in 1959 with 7 countries participating, is today considered the world championship in mathematics for high-school students (IMO, 2015). The Olympiad has gradually expanded to include more than 100 countries from 5 continents and is held annually in a different country (see Rodríguez, 2011). But today, as statistics educators see the need to encourage statistical literacy among students, the popularity of statistical competitions has increased. Particularly as statistics educators believe it is necessary to provide an experimental environment with real data to answer relevant questions about the real world (Sanchez et. al, 2011). After all, evidenceinformed decision making at all levels of society will not be possible without access to data and information. Informed decision making will also require the ability to understand how the statistical information has been compiled and a critical view about the quality of statistical information. In fact, statistics is more than a branch of mathematics supported by data analysis: it involves experience planning and problem-based matters that need careful thinking and reasoning (Garfield, 2002; Garfield \& Gal, 1999).

Many statistical offices have embraced the idea of organising statistical competitions based on real data (Sanchez et. al, 2011). In Italy, the Italian Statistical Society and the National Statistics Office jointly organise a national competition for the best work in statistics, such as an investigation, an article or a study. The collaboration includes provision to students and teachers of statistical data and a guide for the use of data and metadata. In Portugal, the ALEA project, that links the statistical office and secondary schools, launched $A L E A$ 's Challenges, an on-line competition containing everyday life problems based on daily news.

The ISLP also runs the 'Best Cooperative Project Award' in statistical literacy. Like the poster competition, the best cooperative project takes place every two years, in recognition of outstanding, innovative, and influential statistical literacy projects that affect a broad segment of the general public and are the result of cooperation between 
different types of institutions, such as NSIs, schools, statistical societies, media, libraries, and so forth. Candidate projects must be topical and have the potential to remain so in the future, provide free access to the project resources and membership, educate on concepts of statistical theory and data analysis, including their use in the development of information about countries and societies and their application in a broad spectrum of disciplines and areas of society. Projects must include pedagogically sound content suitable for and attractive to a wide audience, have fun appeal and invite participation. Past winners have usually involved two or more institutions that would typically not work closely together. Examples are projects that involve cooperation between several institutions like ALEA (n.d.) the Post-Graduate Program in Official Statistics (see Harraway \& Forbes, 2013), CensusAtSchools (n.d.), and Exploristica (n.d.) who were the winners in 2007, 2011, 2013, and 2015.

There are several other statistical literacy competitions running in many countries. Japan has run a national statistics competition since 1953 (Watanabe, 2014). In Ireland, the John Hooper Medal for Statistics Competition is a poster competition, aiming at improving students' abilities to describe their environment with the help of statistics and to use statistics as a tool for making sense of daily life. This competition is committed to fostering a love of exploration and learning and encouraging both statistics and team work in post-primary students (MacFeely \& McCuirc, 2013). The Australian Bureau of Statistics, in partnership with several Australian universities, sponsors a poster competition (AMT, 2016). Moreover the Statistical Society of Australia runs a secondary schools poster competition at national level. This competition hopes to inspire school teachers and students with practical applications of curriculum content, build relationships between universities, schools, teachers, students and professional societies (in other words, build a community) and increase the accessibility of higher education. And it also aspires to improve students' abilities to succinctly communicate key information. In the USA, the American Statistical Association (ASA) has also its own poster and project competitions (ASA, 2015), that have been organised for many years.

\subsection{THE ISLP POSTER COMPETITION}

Poster competitions are increasingly becoming a popular way of motivating students and teachers to advance statistical literacy. The main goal of the ISLP Competition, running since 2008, is to increase awareness of statistics among students and teachers throughout the world, to promote statistical literacy resources and to bring together stakeholders interested in statistical literacy in each country. To enter the poster competition, students must work as a team, investigate real questions using data, use calculation and graphical skills, interpret statistical results, and develop written communication skills.

\subsection{WHAT MAKES A GOOD POSTER}

A poster is a one-page presentation that tells a clear story about a set of data. It should be simple and have a logical progression, including graphs and descriptive summaries, and contain commentary on the meaning of the data; a poster should also be visually attractive and creative. All posters must contain a goal, a clear methodological approach, main findings, and conclusions. Posters should be self-contained, meaning that readers should need no extra material or information to understand their content. In the USA, the scoring rubric of the ASA project competition contains seven different measures that are assessed using a 4-point scale across seven modalities (see Table 1). 
The goal is to design a poster with a story, involving the several stages of statistical processes, connecting the proposed question to the suggested conclusion. In assessing the quality of posters, the ISLP uses criteria that slightly differ from the ASA (see also the Appendix): For every competition, the jury defines their own scheme for grading in order to prioritise particular criteria. These schemes usually adopt a 5-point Likert scale.

Table 1. Comparison of the criteria catalogue between ASA and ISLP

\begin{tabular}{ll}
\hline ASA catalogue of criteria & ISLP criteria (ISLP, n.d.) \\
\hline (1) statistical question; & (1) clarity of message; \\
(2) data collection; & (2) data collection; \\
(3) data display; & (3) analysis and conclusions; \\
(4) data analysis; & (4) graphs and tables; \\
(5) conclusion; & (5) presentation; and \\
(6) reflection on process; and & (6) creativity/importance. \\
(7) overall presentation. & \\
\hline
\end{tabular}

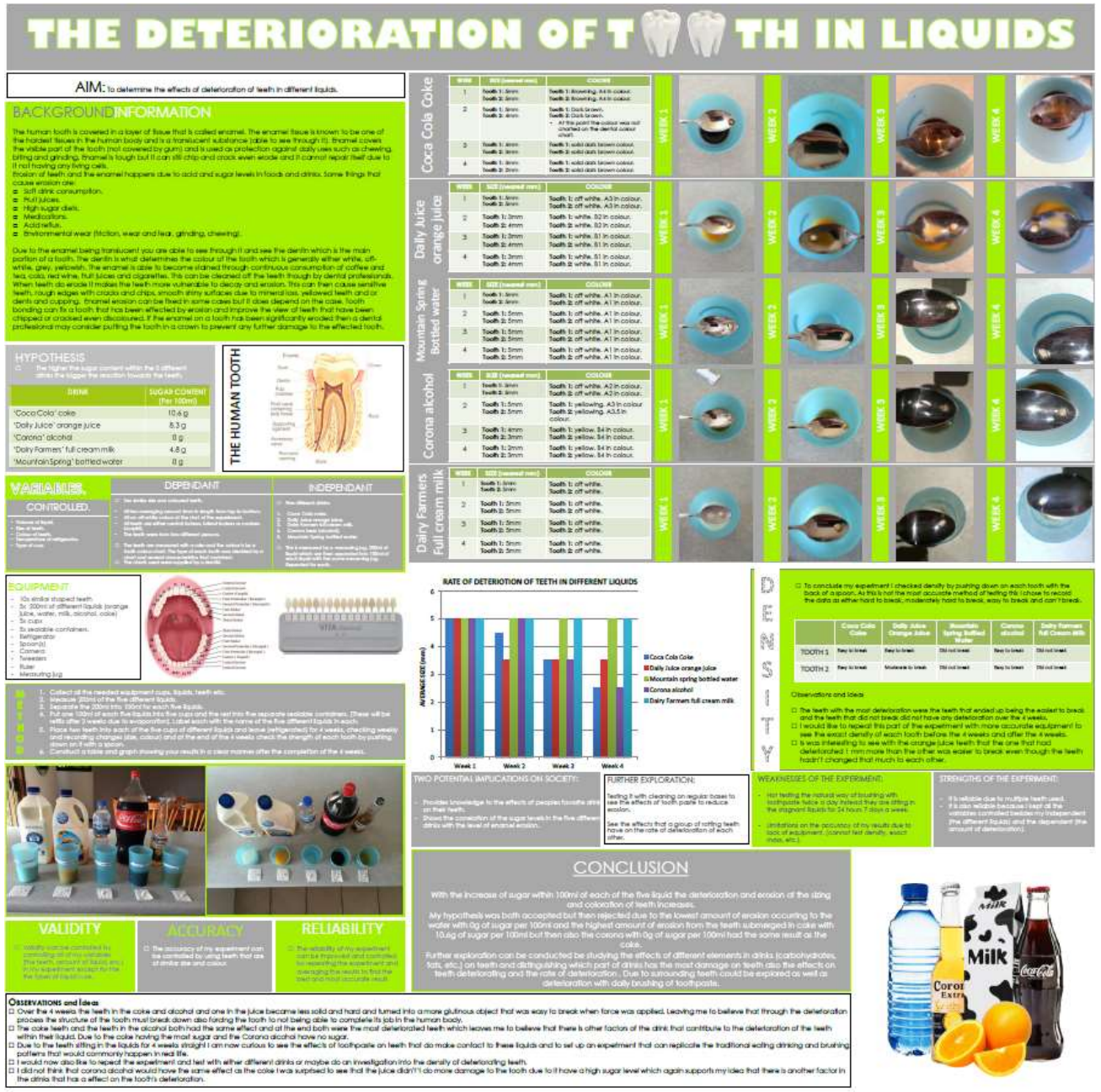

Fig. 1. First prize of the ISLP Poster Competition (Younger Division) 2014-2015 


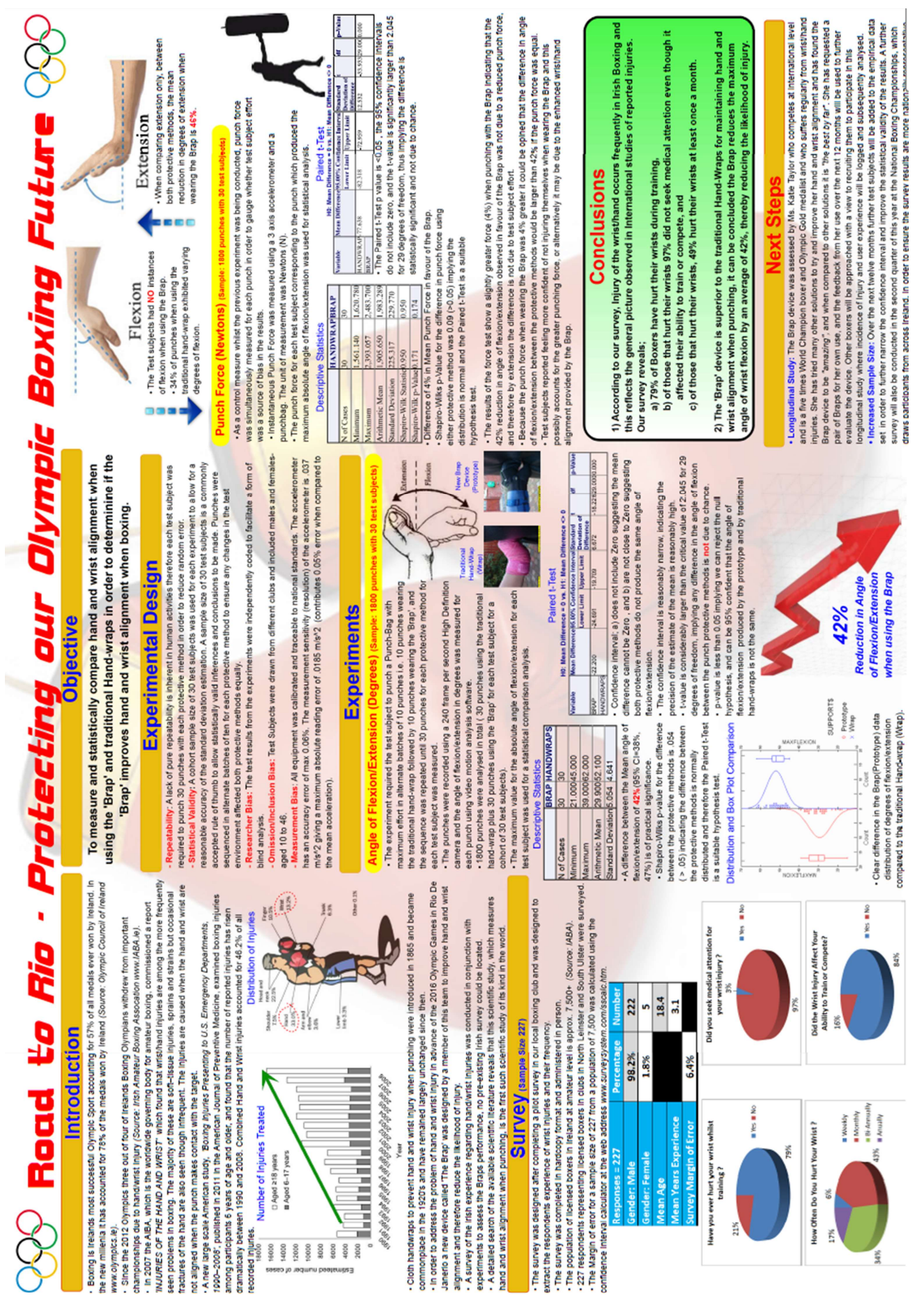

Fig. 2. First prize of the ISLP Poster Competition (Older Division) 2014-2015 
In the checklist used by the ISLP to grade posters, there are many features to verify. For example, a poster must be self-contained in the sense that it must be understandable without access to additional information. The poster must also be logical in structure, meaning that the reader is not confused by the sequencing or the argument presented. Data collection methods should be transparent and conclusions must be supported by the data. A poster should be neat, uncluttered, with an eye-catching, original design and address an interesting question. Presented data must be relevant to the research question or hypotheses, and analysed with appropriate use of graphs, tables, and statistics.

The winners of the 2014/15 ISLP Poster Competition are discussed below, in order to illustrate some of the features outlined above (see Figure 1 and 2). The competition was open to teams of 2-3 students in two age divisions: students born in 1999 and younger (Younger Division), and students born in 1996 and younger (Older Division). In each country, a coordinator encouraged schools and teachers to participate, provided resources and guidelines, and arranged a panel and the judging process. Posters were judged in their respective countries before they went on to the international level.

In both categories, the graphical representation of the winning teams was adequate, clear and expressive. The winners of the first prize in the Younger Division were from Australia (T. Hayter, T. Cheetham, and B. Khoury). To answer their research question (whether higher sugar content in a selection of different drinks has a negative outcome for teeth), they tested several drinks. They measured $200 \mathrm{ml}$ of five different drinks, placing two teeth into each of the five cups of different liquids (refrigerated) for 4 weeks. The teeth were checked weekly and changes recorded (size, colour, etc.) and at the end of the 4-week period, the strength of each tooth was determined by pushing down on it with a spoon. Finally the students constructed a table and a graph showing their results in a clear manner. The winners of the Older Division (R. and S. Ni Dhonnachadha, 2015) investigated whether a new method of protecting boxers' wrists was in fact superior to the traditional method. A striking feature of this poster was the clarity they demonstrated in outlining not only their objective, methods and design used but also their reasoning behind the choices. Results and conclusions were explained clearly, as were steps taken to deal with various types of bias.

\section{KEY SUCCESS FACTORS IN THE ISLP POSTER COMPETITION}

\subsection{INSTITUTIONAL COOPERATION}

Given the complexity of statistical education, it comes as no surprise to learn that several countries have identified institution cooperation as a key factor of success. No single institution, whether statistical or educational, can optimise outcomes alone. However, through institutional cooperation, the ability to successfully run a statistical competition and address deficiencies in literacy improves immeasurably. Whether raising funds, providing data and technical or logistical expertise, or assisting in marketing and media capture, the various institutions can bring in something extra to support the running of the competition. When we look across countries participating in the ISLP competitions, we see that institutional cooperation is a feature of many entries. For example, Finland, India, Japan, Russia, Spain, Italy, Ireland and New Zealand have all identified institutional cooperation as a centrally important feature of their model to improve statistical literacy. Typically, we see the types of institutions included are: NSIs, secondary and tertiary educational institutes, government departments for education (or science and technology), statistical associations and other organisations, such as mathematics curriculum boards. 
As outlined above, the importance of institutional cooperation is recognised by the ISLP in the Best Cooperative Project award. A good example of this is the 2015 winner 'Exploristica' (see Section 4.6). Another well-known example is CensusAtSchools, which was developed by the Royal Statistical Society Centre for Statistical Education in cooperation with the Office of National Statistics in the UK.

In Finland the 'Statistical Yearbook for Children' project has been developed in cooperation between Statistics Finland, Forum Virium, City of Helsinki Urban Facts, Helsinki Mathland, the Summamutikka centre, and Aalto University. This project has developed the 'Tilastrofi' operating model, where the objective is to encourage children to examine and develop their own life and produce information about issues that matter to them through statistical methods. Tilastrofi (2015) contains various tools for children to define their research questions, collect, analyse and visualise data. These tools, like statistics and data visualisations produced by the students are made accessible on the web (Tilastro, 2015). The project is currently directed at schools in the Helsinki region for children aged between 7 and 15 .

The aim is to expand the project to the entire country by 2017 . The work guides children towards cooperation, and developing and influencing their own operating environment. For schools, Tilastrofi offers a participatory way to support the statistics curriculum and produce new data on, for example, students' well-being, and use these data in the school's decision making. Statistics Finland has, from the start, been part of the project as an expert guide, both when it comes to the correct use of statistics and in providing reliable data. The e-learning materials for the eCourse in statistics (Tilastokoulu) are also used as support material in school projects. The Tilastrofi project culminates in a gala at Statistics Finland. At this event children present their work both in a poster exhibition and in the auditorium where statistical experts give feedback on their work. The best studies are rewarded. The events have generated a lot of media interest with some children being interviewed on television (Helenius, 2015).

\subsection{CELEBRATION}

Another important factor, particularly for children, is the celebration of achievement to positively reinforce their work - a significant feature of education. Many countries make great efforts to celebrate their winners and acknowledge the efforts of all other participants, too. There are, no doubt, many reasons for this. First and foremost, it is important to recognise the achievements of the students who have participated and won. But such events provide opportunities to raise awareness of the need to improve statistical literacy in the community. They also help to attract media attention, which in turn, helps to attract more participants and highlight the efforts of the institutions involved. This aspect is noted, for example, by Finland, Japan, India, Ireland, Poland, and New Zealand.

Some countries use prize-giving ceremonies to allow students to present their work to peers, parents, teachers, and - in some cases - even to government ministers, university or NSI presidents. Countries have adopted slightly different approaches vis-à-vis awards. Not all countries award prizes, but rather give other awards. Finland, India, Ireland and Japan all present prizes (money, medals or other awards) but this approach appears to be more the exception than the norm.

Another interesting common factor identified is the important catalytic role of international celebratory events such as World Statistics Day (the first of which was held on 20-10-2010, a memorable date) and other national statistical days. These official days can create the opportunity or space to allow NSIs or other institutions to think beyond their immediate mandate or bring a little extra creativity to their approach. They also tend 
to bring more focus or heighten awareness of the need for marketing and media in order to mark the day or event. Several countries, including, for instance, Finland, Iran, Ireland, Italy and Spain have noted, in one way or another, the importance of these days, either for launching or sustaining their efforts.

\subsection{NATIONAL COMPETITIONS}

The ISLP poster competition is biennial; however, many countries run national competitions annually. These national competitions have been identified as a key factor of success in several countries participating in ISLP competitions (Finland, Ireland, Italy, Japan, Korea, Russia, and Spain). Some of these competitions pre-date the ISLP, for example, in Japan. Often these competitions are designed to seamlessly fit with the ISLP parameters and rules so that national winners can represent countries at the ISLP.

The advantages of running a regular national competition are many: for example, it often means that it is easier to maintain an organisational structure and retain the interest of schools and media. An independent national framework often provides a better opportunity to provide feedback to students and develop teaching resources for teachers. In particular, both Finland and Ireland have made great efforts to provide feedback to students so that they can learn from their mistakes but also that other prospective students can learn what makes a good poster. Feedback also safeguards transparency, as all students can view jury feedback on all posters online.

\subsection{SUPPORT FOR TEACHERS}

Support for teachers is also clearly a key factor of success. In many countries, statistics is not formally part of the mathematics syllabi, neither in the mathematics syllabi for students nor for teacher-training, and therefore mathematics teachers may require assistance. This challenge has been recognised in several countries. We see, for example, in Finland, Ireland, Japan, Mexico and New Zealand efforts that have been made to address this gap by providing a variety of support, ranging from teaching basic statistics to teachers or providing resources or other pedagogical materials online (e.g., CensusAtSchool, n.d.; the interactive zone at Central Statistics Office Ireland, CSO, n.d.; the resources pages at ISLP, n.d.). NSIs and other statistical societies have also provided logistical support such as organising national competitions for them.

\subsection{NATIONAL STATISTICS INSTITUTES (NSIs)}

The role of NSIs (and regional statistical institutes) is central to efforts to improve statistical literacy in many countries (Australia, Finland, Ireland, Italy, Japan, New Zealand, Portugal, Russia, Spain, and South Korea). This follows directly from the points above; national and regional statistical institutes may be the only repository of practical statistical expertise and data available so that their participation is a boon to any statistical literacy programme or competition. NSIs also have important national reach, typically with access to other government departments and resources. Although not all NSIs see statistical literacy as falling within their mandate, MacFeely (2016) has argued to the contrary, saying that NSIs have an obligation to improve statistical literacy.

Since the ISLP competition started, only two countries have won the senior age category, Finland (2008/09' 2010/11' and 2012/13) and Ireland (2014/15; see ISLP, n.d.). A short outline of how each of the NSIs in these countries has approached the ISLP is presented to illustrate why their contribution has been so important. 
Finland Statistics Finland has been actively involved in the ISLP since the beginning. Young people are the future data users, decision makers, and data suppliers (Helenius, 2016). Schools' awareness of and interest in the ISLP competition has grown continuously, which has been the result of active marketing and communication towards schools.

Statistics Finland also has a long history of cooperation with educational institutions, going back almost twenty years. The statistics institute sees educational institutions as strategic partners and cooperation with them as an investment in the future, but one investment that requires a long-term approach. For example, in the 2010-11 competition only 200 students from Finland participated. Today, for the 2016-17 competition more than 1,000 students have signed up. Designing statistical posters (or posters in general) has not generally been a common method of teaching in Finnish schools but now, thanks to the ISLP, teachers are beginning to find that posters are an excellent teaching tool.

In Finland, the competition is, in addition to Statistics Finland, organised by the Finnish Association of Teachers of Mathematics, Physics, Chemistry and Informatics (MAOL), and the Finnish Statistical Society. Statistics Finland is responsible for the practical organisation of both the national and international competitions, and MAOL and the Finnish Statistical Society support the marketing of the competition and participate in the work of the national jury. Both Statistics Finland and the Finnish Statistical Society have participated in training mathematics teachers. These workshops for teachers have proven a very fruitful form of cooperation. During these events Statistics Finland typically demonstrates, for example, how statistics can be utilised in teaching and explains how posters and the national and ISLP competitions can be used as a teaching method.

The three top teams in both competition categories (young and older) are well rewarded with money and other awards. The winners also attend a two-day event in Helsinki that includes the award ceremony and other programmes for young people. The winners of the upper secondary school category also get a student place at the University of Helsinki to study statistical science.

Statistics Finland sees the benefits of arranging the statistical poster competitions as it helps open the door directly to school education by offering useful tools to support teaching. It is a win-win situation for both parties, both for the statistical institutes and the educational institutions.

Ireland The role of the Central Statistics Office (CSO) in the success of Ireland's participation in the ISLP cannot be overstated. In 2007, the Senior Management Committee of the CSO decided that improving statistical literacy in Ireland fell within the mandate of the office. As a consequence, the CSO launched an education outreach programme Investing in the Future (MacFeely \& McCuirc, 2013). This programme focused on three distinct targets: (1) primary and post primary education; (2) third level and continued professional development; and (3) media and wider society.

As part of this programme, the 'John Hooper Medal for Statistics' competition was launched on World Statistics Day, 20 October, 2010. This poster competition is now run annually and is combined with the ISLP poster competition, in the years where the ISLP runs a competition. The competition reaches out to post-primary school students, encouraging them to explore an issue and present their findings in a poster format, working as a team and using their mathematics and statistics skills.

In the most recent competition (2015) 1,435 students from schools across the island of Ireland registered. 950 students actually submitted a total of 379 posters by the closing date. Judging is blind and takes place over a number of weeks in three phases. Firstly, two 
statisticians at the CSO long-list the initial posters based on a consistent set of judging criteria. In 2015, 42 posters went forward to the second phase. This second phase involves a more rigorous review of the long-listed posters. Between 15 and 20 CSO staff from a variety of backgrounds (gender, age, grade, section, specialisation, and location) use the same set of criteria used by the initial judges. In 2015, following the second phase of judging, 16 posters were short-listed to go forward to the final judging panel. In the final phase, the panel consists of a CSO chair and a number of external, independent judges from various mathematics, statistics or teaching backgrounds. This panel meets for a day, and again using the same set of criteria as in previous judging phases, selects the winners and runners-up. The chair of the final judging panel then discusses the overall quality of the posters to determine any feedback messages from the judges to the students to improve the quality of posters in future competitions (for illustrative purpose, see CSO, n.d.).

Winning posters are announced and links to the winning and short-listed posters are made public on the CSO website. For example, in 2015, 16 posters were published. Posters are listed as first, second, third, and order of merit. Students, teachers and schools are acknowledged. Certificates are sent to all students who submitted a poster. Special certificates are awarded to successful students and schools. During 'Maths Week', which usually takes place in October each year, a special prize-giving ceremony is held in the Department of Education headquarters to which students, teachers, parents, educators, the media and other interested parties are invited. A government minister attends and awards the John Hooper Medal for Statistics and presents the prizes for the competition. At this event the next John Hooper Poster competition is simultaneously launched.

Thus we see that the Central Statistics Office in Ireland makes a significant contribution, both in terms of financial resources (prize money), expertise and resourcesin-kind (statistician time and feedback to students), provision of important organisation and infrastructure (organising judging panels, prize-giving ceremonies and a dedicated webpage, see CSO, n.d.) and networking and liaison with other relevant stakeholders and government departments ensuring a government minister presents the prizes, getting expert feedback from the Department of Education \& Skills, Irish National Council for Curriculum Assessment, the National Centre for Technology in Education (see MacFeely and McCuirc, 2014).

\subsection{ACADEMIC SUPPORT}

Beyond teachers, academic support is also identified as being very important. This is particularly true at the tertiary level where academic centres often house not only statistical expertise but are frequently data repositories, too. Perhaps most importantly they are often focal innovation centres. A good example is INCENSE (n.d.) - a set of effective data visualisations developed in the SMART Centre at Durham University together with the UK Office of National Statistics (Nicholson, Ridgway, \& McCusker, 2014). INCENSE was designed to make census data more accessible through data visualisation and to understand how politicians and journalists used 2011 census data when it was released.

Typically, universities are less constrained than NSIs and thus may have more experience in dealing with some newer aspects of data, such as harvesting social media or big data. We can see that academia has played a central role in many countries (Iran, Ireland, Japan, New Zealand, Poland, and Russia). Furthermore, academia are often better at developing or integrating geo-spatial and statistical domains, which is often important for presenting, visualising and explaining data $-\mathrm{a}$ key aspect of statistical posters. 
Academic and resource support can also be provided by statistical societies. A good example of this is in Portugal where the Statistical Society (Sociedade Portuguesa de Estatística) developed a tool called 'Exploristica - Adventures in Statistics' (Exploristica, n.d.) in cooperation with the Portuguese NSI (Instituto Nacional de Estatística). It is an itinerant exhibition consisting of various interactive modules with the aim of bringing the fundamentals of statistics and probability to educational communities, conveying the concepts in a practical and experimental way. Exploristica's target audience is secondary school students (12 to 17 years). The tool describes five important phases in the statistical process - select, collect, describe, estimate, and interpret. Students interact with modular content such as games and other interactive experiences. The main concepts taught are samples and census, location and dispersion measures (mean, median, standard deviation), graphs (box and whiskers, bar plots, histograms), random and non-random sampling, relative frequency, and probability. Participants form groups with three elements and go through the games (the modules) with the 'explorer sheet', where they construct graphs, take notes, and draw conclusions. The 'Exploristica - Adventures in Statistics' won the Best Cooperative Project in 2015 (see ISLP, n.d.).

\subsection{TECHNOLOGY}

Technology is playing an increasingly important role in our day-to-day lives. Different countries have embraced technology and incorporated it into their competitions. For example, Finland, Ireland and Russia use the web to exhibit successful posters. Australia is harnessing social media, and Italy has used ICT to develop tools and games to engage students. Several countries only accept electronic posters whereas other countries continue to accept paper posters (e.g., India) which may be very practical as electronic posters may prohibit entries in some countries. As technology develops and the digital divide reduces, we anticipate that technology will become a key success factor to improve education in the future.

\section{CONCLUSIONS}

The ISLP poster award is built on experiences from more traditional mathematics competitions. The competition is designed to encourage statistical literacy among students by creating a space where students can explore real-world issues by experimenting with real data. In doing so, the ISLP hopes to foster an open and inclusive global statistical community that includes not only statistical and academic institutions but also schools, government departments, libraries, and anyone else who is interested.

As noted in the introduction, we have not offered an exhaustive list of success factors. For example, although not discussed anywhere in the ISLP newsletter, experience has shown that alignment of the competition schedule with the school year is extremely important. This has proven challenging for the ISLP competition, which straddles both the northern and southern hemispheres with very different school years. Experience has also shown that selecting a theme can reduce the number of entries if it is too narrow or specialised - for example, even a topic as broad as agriculture may alienate children from urban centres. Experience has shown too, that providing assistance to schools and teachers can ultimately encourage them to inspire their students to participate in statistical activities and competitions. Another important lesson, exemplified by Ireland, is to encourage students, teachers and coordinators to never become disheartened. When Ireland first entered the ISLP, it placed $8^{\text {th }}$ in the older category; in their second attempt, they placed $2^{\text {nd }}$ while in their third attempt, Ireland won the competition. 
Our hope is that this paper proves useful for countries considering involvement in the poster competition or simply contemplating how to improve statistical literacy. We have highlighted factors that appear to have contributed to success. These factors were identified from articles in the ISLP newsletters and so are unlikely to provide a comprehensive list of factors or to reflect experiences in every country. As the articles in our newsletter get more diverse, we anticipate that further cultural factors will be identified.

Today the ISLP competition operates in 31 countries. This competition plays a small but important role in bringing the spirit of enquiry and exploration to young people. We sincerely hope that, through participation, more and more children will have their curiosity ignited about the world around them, whether economic, political, social or physical. Bringing statistical literacy to young minds will prepare future generations for life in a world, increasingly reliant on data. By helping children to understand what is going on, we are contributing to their ability to participate in life and citizenship.

\section{REFERENCES}

ALEA (n.d.). Australian Literacy Educators' Association. [Online: www.alea.edu.au/] AMT (2016), Australian Mathematics Trust (AMT).

[Online: www.amt.edu.au/aspcnews01.html]

ASA (2015). Student competitions. American Statistical Association.

[Online: www.amstat.org/education/studentcompetitions.cfm]

Ben-Zvi, D. \& Garfield, J. (2004). Statistical literacy, reasoning, and thinking: Goals, definitions and challenges. In D. Ben-Zvi \& J. Garfield (Eds.), The challenge of developing statistical literacy, reasoning and thinking (pp. 3-15). Dordrecht: Kluwer.

CensusAtSchools (n.d.). A Tool to Support the Maths Curriculum.

[Online: www.censusatschool.ie/en/home]

CSO (n.d.). John Hooper Medal for Statistics. Central Statistics Office. [Online: www.cso.ie/en/newsandevents/johnhoopermedalforstatistics2015competition/]

Dhonnachadha, R., Dhonnachadha, S. (2015). Road to Rio - Protecting our Olympic boxing future. St. Vincent's Secondary School. ISLP Poster Competition, Rio de Janeiro, Brasil.

Exploristica (n.d.). Adventures in Statistics. Portuguese Statistical Society. [Online: www.exploristica.com/]

Garfield, J. (2002). The challenge of developing statistical reasoning. Journal of Statistics Education, 10(3). [Online: ww2.amstat.org/publications/JSE/]

Garfield, J. \& Ben-Zvi, D., Chance, B., Medina, E., Roseth, C., \& Zieffler, A. (2008). The discipline of statistics education. In J. Garfield \& D. Ben-Zvi, Developing students' statistical reasoning (pp. 3-19). New York: Springer.

Garfield, J., \& Gal, I. (1999). Teaching and assessing statistical reasoning. In L. Stiff \& F. R. Curcio (Eds.), Developing mathematical reasoning in grades K-12. 1999 Yearbook (pp. 207-219). Reston, VA: National Council Teachers of Mathematics.

Harraway, J. A. \& Forbes, S. D. (2013). Partnership between national statistics offices and academics to increase official statistical literacy. Statistical Journal of the International Association for Official Statistics, 29(1), 31-40.

Hayter, T., Cheetham, T., \& Khoury, B. (2015). The deterioration of teeth in liquids. Lisarow High School. ISLP Poster Competition, Rio de Janeiro, Brasil.

Helenius, R. (2015). You learn to use statistics. Proceedings of the $60^{\text {th }}$ world statistics congress (pp. \%\%). The Hague: International Statistical Institute.

[Online: www.isi-web.org/index.php/publications/proceedings] 
Helenius, R. (2016). Facing the future with knowledge - Cooperation with educational institutions. Proceedings of Nordisk Statistiker mote (in press).

IMO (2015). International Mathematical Olympiad. [Online: www.imo-official.org/]

INCENSE (n.d.). Influencing Policy and Practice. SMART Centre at Durham University and the Data Visualisation Centre at ONS.

[Online: www.dur.ac.uk/education/research/groups/?mode=project\&id=612]

ISLP (n.d.). International Statistical Literacy Project. IASE and ISI.

[Online: iase-web.org/islp/Poster_Competition_2014-2015.php]

MacFeely, S. \& McCuirc, E. (2013). Another brick in the wall - improving statistical literacy in Ireland. In S. Forbes \& B. Phillips (Eds.), Proceedings of the IASE/IAOS satellite conference on statistics education for progress $(10 \mathrm{p}$.$) . The Hague:$ International Statistical Institute. [Online:

iase-web.org/Conference_Proceedings.php? $\mathrm{p}=$ Stats_Education_for_Progress_2013].

MacFeely, S. \& McCuirc, E. (2014). More ways to heaven than one: improving statistical literacy in Ireland. In K. Makar, B. de Sousa, \& R. Gould (Eds.), Sustainability in statistics education. Proceedings of the Ninth International Conference on Teaching Statistics (ICOTS9) (5 p.). The Hague: International Statistical Institute.

[Online: iase-web.org/Conference_Proceedings.php?p=ICOTS_9_2014]

MacFeely, S. (2016). The continuing evolution of official statistics: some challenges and opportunities. Journal of Official Statistics, 32(4),789-810.

Nicholson, J., Ridgway, J., \& McCusker, S. (2014). SMARTcensus - Making sense of census data. In K. Makar, B. de Sousa, \& R. Gould (Eds.), Sustainability in statistics education. Proceedings of the Ninth International Conference on Teaching Statistics (ICOTS9) (6 p.). The Hague: International Statistical Institute.

[Online: iase-web.org/Conference_Proceedings.php?p=ICOTS_9_2014]

Nussbaumer Knaflic, C. (2015). Storytelling with data - A data visualization guide for business professionals. New Jersey: Wiley.

Ridgway, J., Smith, A. (2013). Open data, official statistics and statistics education threats and opportunities for collaboration. In S. Forbes \& B. Phillips (Eds.), Proceedings of the IASE/IAOS satellite conference on statistics education for progress $(8 \mathrm{p}$.). The Hague: International Statistical Institute. [Online:

iase-web.org/Conference_Proceedings.php? $\mathrm{p}=$ Stats_Education_for_Progress_2013].

Rodríguez, M. I., (2011). Statistics Olympiad at Córdoba, Argentina. ISLP Newsletter, 2(4), 3. [Online: iase-web.org/islp/Publications.php]

Sanchez, J., Forbes, S., Campos, P., Giacche, P., Townsend, M., Mooney, G., \& Helenius, R., (2011). The millennium development goals, national statistical offices, the international statistical literacy project and statistical literacy in schools. Journal of the International Association for Official Statistics, 27(3-4), 157-171.

Tilastrofi (2015). [Online: www.Tilastrofi.fi]

UN Conference on Trade and Development (2016). Development and globalization 2016: Facts and figures. [Online: stats.unctad.org/Dgff2016/]

UN Economic Commission for Europe (2012). Making data meaningful, Part 4: A guide to improving statistical literacy. United Nations, Geneva. [Online: www.unece.org/ fileadmin/DAM/stats/documents/writing/Making_Data_Meaningful_Part_4_for_Web.pdf]

Walsh Jr., T., (2011). Implementing project based survey research skills to grade six ELP students with The Survey Toolkit and TinkerPlots. Journal of Statistics Education, 19(1), 1-27. [Online: ww2.amstat.org/publications/JSE/]

Watanabe, M., (2014). Japanese statistics poster competition marking 61 years of success. ISLP Newsletter, 7(1), 4-6. [Online: iase-web.org/islp/Publications.php] 


\section{APPENDIX \\ CRITERIA FOR THE ISLP POSTER COMPETITION (ISLP, 2015)}

\section{Clarity of the message}

a. Is the poster understandable without extra information?

b. Are the objectives, research question or hypotheses clear?

c. Are the results and conclusions clear?

d. Is the poster clearly and logically set out?

\section{Data collection}

a. Are the collected data appropriate for answering the research question?

b. Are the data collection methods clearly stated? (e.g., primary data collection by print, telephone, web survey, or other measurement tools; or secondary sources such as published reports, databases etc. are cited)

c. Has the quality of the data been considered? (i.e., accuracy of measurements, size of the sample, reliability of sources, etc.)

d. Are the data sources referenced in the poster?

\section{Analysis and conclusions}

a. Are the data analysed in terms of the research question or hypotheses?

b. Is the analysis appropriate for the kind of data collected?

c. How well is the research question answered?

d. Are there conclusions and are they supported by the data?

e. Are there any limitations discussed or improvements for future studies suggested?

\section{Graphs and tables}

a. Are the graphs/tables/statistics appropriate for displaying and summarising the data?

b. Are there enough graphs/tables from different perspectives?

c. Does every graph/ table add something to the poster?

d. Are the graphs/tables properly titled and explained?

\section{Presentation}

a. Is the poster readable from 2 metres ( 7 feet) away?

b. Is there a good balance between graphs and text?

c. Does the poster look neat?

\section{Creativity / importance}

a. Is the research question creative, original?

b. Can the study answer an interesting question?

c. Is the design creative and original?

d. Is the poster eye-catching?

STEVE MACFEELY

UN Conference on Trade and Development

Palais des Nations, 8-14 Avenue de la Paix

1211 Geneva 10

Switzerland 